\title{
Fish Bone as a Source of Raw Material for Synthesis of Calcium Phosphate
}

\author{
Tarcília Henrique Amaral Corrêa ${ }^{a}{ }^{\circledR}$, José Nilson França Holanda ${ }^{a, b}(\mathbb{C}$ \\ ${ }^{a}$ Programa de Pós-Graduação em Ciência e Engenharia de Materiais - PPGECM, Universidade \\ Estadual do Norte Fluminense - UENF, 28013-602, Campos dos Goytacazes, RJ, Brasil \\ ${ }^{b}$ Laboratório de Materiais Avançados - LAMAV, Universidade Estadual do Norte Fluminense - \\ UENF, 28013-602, Campos dos Goytacazes, RJ, Brasil
}

Received: August 27, 2019; Accepted: September 3, 2019

\begin{abstract}
Fish bone is rich in calcium carbonate, which makes it an alternative source of low cost calcium carbonate for the synthesis of calcium phosphate bioceramic for use in bone regeneration. The calcium phosphate bioceramic was prepared by a wet precipitation method with acid and base reactions. The synthesized bioceramic was characterized in terms of X-ray diffraction (XRD), scanning electron microscopy (SEM/EDS), thermogravimetric analysis (TGA), Fourier transform infrared spectroscopy (FTIR), average crystallite size and refinement by the Rietveld method for the quantification of crystalline phases. The results indicated the formation of a biphasic calcium phosphate bioceramic comprising 67.6 $\%$ of $\beta$-calcium pyrophosphate ( $\beta$-CPP) and $32.1 \%$ of $\beta$-tricalcium phosphate $(\beta$-TCP). This biphasic calcium phosphate bioceramic synthesized using fish bone waste presented nanostructured nature with an average crystallite size of $69.58 \mathrm{~nm}$, which is very promising for biomedical applications.
\end{abstract}

Keywords: Calcium phosphate, biphasic bioceramic, fish bone waste, nanocrystallites.

\section{Introduction}

Around the world, bone defects are caused by trauma, excision, mutilation, extraction, or some abnormal developed tissue, resulting in a major global health problem around two millions bone repair procedures performed annually ${ }^{1}$. About thirty years ago, the field of materials engineering developed bone tissue engineering to induce bone regeneration, also called bone grafts, which have been shown to have excellent osteogenic capacity, osteoinduction, and osseointegration ${ }^{2}$. These materials were then called biomaterials or bone substitutes. It is well known that the biomaterials most commonly used for bone substitution are those based on calcium phosphate (Ca-P), such as hydroxyapatite, tricalcium phosphates, amorphous phosphate, dicalcium phosphate, among others. Due to the structural and chemical similarities with bone, calcium phosphate-based biomaterials have good biocompatibility, bioactivity and osteoconductivity with implanted tissue ${ }^{3}$.

One of the forms of calcium phosphate that has a high potential to be used as bone replacement material or bone graft is calcium pyrophosphate $\left(\mathrm{CPP}, \mathrm{Ca}_{2} \mathrm{P}_{2} \mathrm{O}_{7}\right)$. The $\mathrm{CPP}$ presents a biological response similar to that of the hydroxyapatite (Hap) for the formation of a new bone. The CPP proved to be more biocompatible to bone tissue than to Hap ${ }^{4}$. In fact, Hap particles have an inhibitory effect on the growth of osteoblast cell cultures ${ }^{5}$. This fact has attracted increasing interest in other calcium phosphate based materials ${ }^{4,6-9}$.
In Brazil, the aquaculture sector has been showing great prominence in the last years in the growth especially in the production of fish (fish farming). Tilapia is the most commonly produced freshwater fish species in the world, intended for fillet production ${ }^{10,11}$. However, activities related to fish production generate a large amount of solid waste in the form of carcasses (fish bones), which is usually discarded in the environment (rivers, landfills, and common garbage) inadequately. This causes pollution to the environment and great risk to public health ${ }^{12,13}$. This type of solid residue is rich in calcium carbonate. Therefore, it has great potential to be reused as an alternative source of calcium carbonate for the production of biocements based on calcium phosphate for regeneration or replacement of the bone tissue in medical and dental applications. In fact, several studies have demonstrated the use of alternative sources with high calcium carbonate content for the synthesis of biocements based on calcium phosphate ${ }^{14-16}$.

The aim of this work is to study the possibility of using fish bone waste (tilapia carcasses) from aquaculture sector in the synthesis of calcium phosphate bioceramic for use as bone regeneration material.

\section{Experimental Procedure}

The fish bone waste sample (tilapia carcasses) was supplied from a local fish market, Muriaé-MG, Brazil. Initially, the waste sample was washed with running water at $70{ }^{\circ} \mathrm{C}$ to facilitate the removal of the glued meat to the bone. 
Then, it was dried at $110^{\circ} \mathrm{C}$ for $24 \mathrm{~h}$ to remove moisture, crushed into powder, and sieved through a 140 mesh sieve (106 $\mu \mathrm{m})$. Mineralogical analysis via X-ray diffraction indicated that the cleaned tilapia carcasses powder is composed of hydrated hydroxyapatite $\left(\mathrm{Ca}_{10}\left(\mathrm{PO}_{4}\right)_{6}(\mathrm{OH})_{2}\right)$. Chemical analysis determined by using an energy-dispersive X-Ray spectrometer (EDX 700, Shimadzu) indicated that the cleaned tilapia carcasses powder is essentially composed of calcium $(\mathrm{Ca})$ and phosphorus $(\mathrm{P})$.

The calcium phosphate bioceramic was synthesized from fish bone waste (tilapia carcasses) by the acid-base precipitation method ${ }^{17}$, by using the chemical reagents $\mathrm{HNO}_{3}$ (Vetec, 65\%) and $\mathrm{Na}_{2} \mathrm{HPO}_{4}$ (Sigma-Aldrich, 98\%). Initially, the cleaned tilapia carcasses powder was slowly added in $\mathrm{HNO}_{3}$ solution (1 M) under constant stirring for $2 \mathrm{~h}$, resulting in the formation of the $\mathrm{Ca}\left(\mathrm{NO}_{3}\right)_{2}$ solution. Then, $\mathrm{Na}_{2} \mathrm{HPO}_{4}$ was slowly added by titrating dropwise to the $\mathrm{Ca}\left(\mathrm{NO}_{3}\right)_{2}$ solution under constant stirring at $50{ }^{\circ} \mathrm{C}$ for $2 \mathrm{~h}$ to form the precipitate. The resulting precipitate from the reaction was vacuum filtered, washed with distilled water and dried at $100^{\circ} \mathrm{C}$ for $24 \mathrm{~h}$. Finally, the dry precipitate (in powder form) was then calcined at $900^{\circ} \mathrm{C}$ for $2 \mathrm{~h}$, by using a heating rate of $10^{\circ} \mathrm{C} / \mathrm{min}$.

$\mathrm{X}$-ray powder diffraction analysis (XRPD) of the synthesized sample was done with a conventional diffractometer (Ultima $\mathrm{IV}$, Rigaku) using $\mathrm{Cu}-\mathrm{K} \alpha$ radiation. The $\mathrm{XRD}$ result was refined using the Rietveld method ${ }^{18,19}$ for the quantitative identification of the crystalline phases formed. The average crystallite size (D) was calculated by using the Scherrer equation according to $\mathrm{D}$ $=0.9 \lambda / \mathrm{B} \cdot \cos ($, where $\lambda$ is the wavelength of $\mathrm{Cu}-\mathrm{K} \alpha$ radiation, $\mathrm{B}$ is the full width at half maximum of the calcium phosphate line, and ( is the diffraction angle. The morphology of the synthesized powder particles was observed using a scanning electron microscopic (Quanta SEM, FEG 250) attached with an energy dispersive X-ray spectrometer(EDS). Thermogravimetric analysis (TGA) of the synthesized powder was carried out with a TA Instrument SDT-2960, by using a heating rate of $10{ }^{\circ} \mathrm{C} / \mathrm{min}$ under air atmosphere. For the identification of the functional groups in the synthesized powder, FTIR (Fourier Transform Infrared Spectroscopy) analysis was performed by using a Spectrum 400 FTIR spectrophotometer (Perkim-Elmer) in the range from 400 to $4000 \mathrm{~cm}-1$.

\section{Results and Discussion}

\subsection{XRD characterization}

The X-ray diffractogram of the synthesized calcium phosphate powder is shown in Fig 1. It was found that the synthesized powder is a biphasic mixture composed of tetragonal structured $\beta$-calcium pyrophosphate $(\beta$-CPP, $\beta-\mathrm{Ca}_{2} \mathrm{P}_{2} \mathrm{O}_{7}$, PDF Card: 01-071-2123) and rhombohedral structured $\beta$-tricalcium phosphate $\left(\beta\right.$-TCP, $\beta-\mathrm{Ca}_{3}\left(\mathrm{PO}_{4}\right)_{2}, \mathrm{PDF}$ Card: 01-072-7587), with predominance of the $\beta$-CPP phase.
It can also be seen that there was the presence of isolated particles of calcium (Ca) identified by the PDF card: 01-0777215. Such a presence of calcium is related to the increase in the $\mathrm{pH}$ of the calcium nitrate solution formed from the fish bone waste, which liberates free calcium. The XRD spectrum after refinement by the Rietveld method $(\mathrm{Rwp}=$ 8.32 and $\chi^{2}=1.01$ ) is shown in Fig. 2, where the amounts of each identified phase are presented. The following values of the formed phases were found: $\beta$-CPP $(67.6 \%)$, $\beta$-TCP $(32.1 \%)$, and $\mathrm{Ca}(0.3 \%)$. This result confirms the predominance of $\beta$-CPP and the secondary phase $\beta$-TCP, as well as the isolated presence of calcium particles formed.

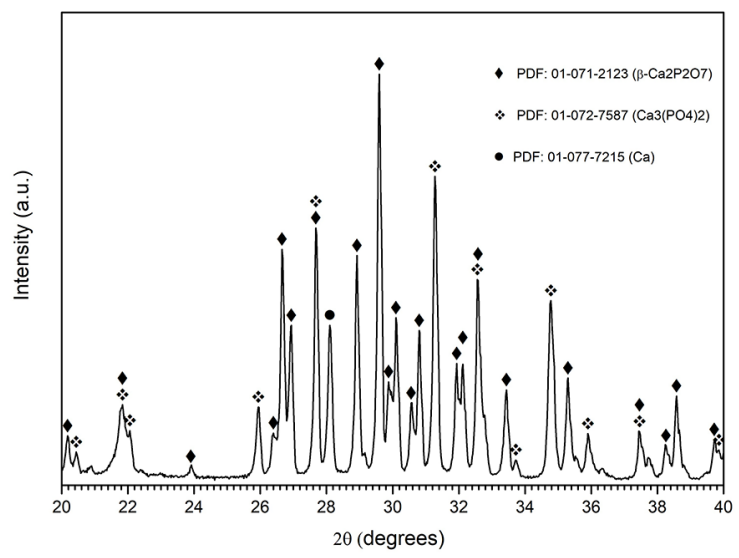

Figure 1. X-ray diffraction pattern of calcium phosphate powder.

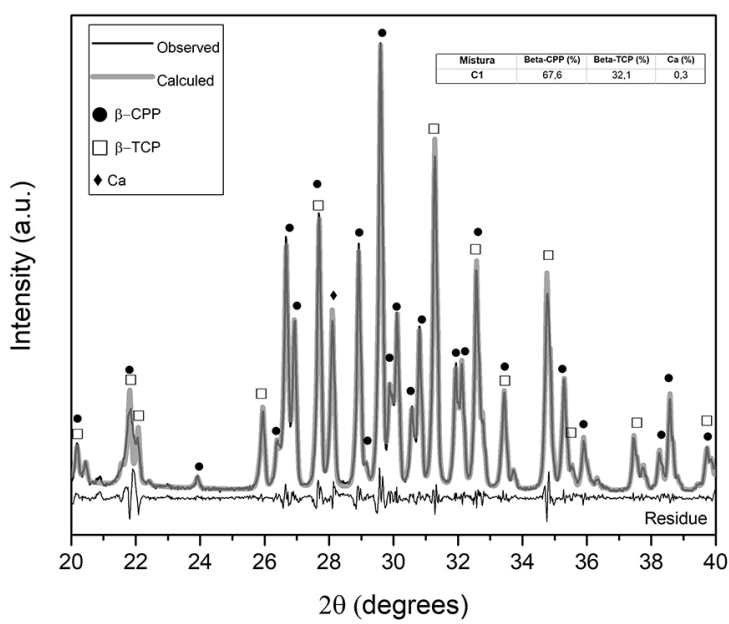

Figure 2. Rietveld analysis pattern for the calcium phosphate powder.

The powder of the synthesized biphasic calcium phosphate mixture has a mean crystallite size obtained by the Scherrer equation within the nanometric range of the order of $69.58 \mathrm{~nm}$. This result is very interesting for biomedical applications, especially in the area of bone tissue regeneration ${ }^{20}$. 


\subsection{Morphological characterization}

The morphological characterization of the synthesized calcium phosphate powder is shown in Fig. 3. It can be seen in the SEM image that the biphasic calcium phosphate bioceramic particles are grouped into the formation of highly agglomerated nanoparticle plates. However, the morphology of the crystals has irregular shapes. Through EDS analysis shown in Fig. 4, it can be noted the presence of three main peaks corresponding to the elements $\mathrm{Ca}, \mathrm{P}$ and $\mathrm{O}$. This result is consistent with the XRD analysis (Fig. 1). The presence of copper $(\mathrm{Cu})$ is related to the metallization technique, while the presence of carbon $(\mathrm{C})$ is due to the carbon ribbon used in the preparation of the sample. The $\mathrm{Ca} / \mathrm{P}$ ratio of the synthesized bioceramic $(\mathrm{Ca}=19.88$ and $\mathrm{P}=14.61)$ obtained through SEM/EDS semiquantitative chemical analysis was approximately 1.36 . Such a $\mathrm{Ca} / \mathrm{P}$ value corresponds to an intermediate value between that of $\beta$-calcium pyrophosphate $(\mathrm{Ca} / \mathrm{P}=1)$ and $\beta$-tricalcium phosphate $(\mathrm{Ca} / \mathrm{P}=1.5)$.

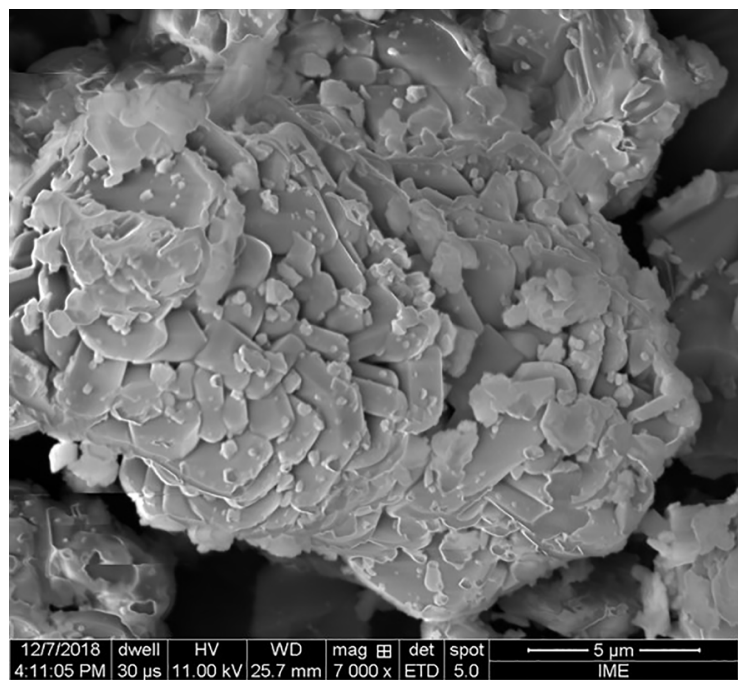

Figure 3. SEM micrograph of the calcium phosphate powder.

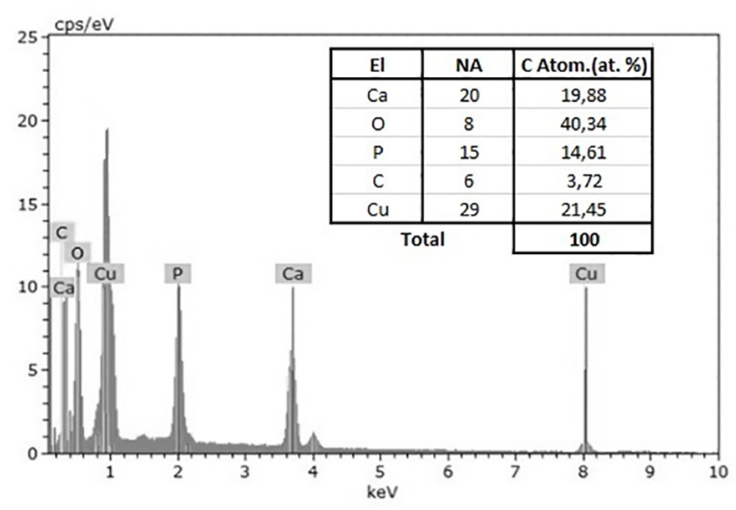

Figure 4. EDS spectrum of the calcium phosphate powder.

\subsection{Thermal characterization}

The Thermogravimetric analysis of the calcium phosphate bioceramic synthesized using fish bone waste (tilapia carcasses) as calcium source is shown in Fig. 5. It was found that the synthesized biphasic bioceramic presented high thermal stability when exposed to temperature up to $1000{ }^{\circ} \mathrm{C}$. The total weight loss was of $1.34 \%$. It can be seen in Figure 5 the presence of two thermal events. The first thermal event (between $\sim 225^{\circ} \mathrm{C}$ and $400{ }^{\circ} \mathrm{C}$ ) totaling $0.71 \%$ of weight loss is attributed to the removal of physically adsorbed water on the particles of the synthesized bioceramic. The second thermal event (between $\sim 400{ }^{\circ} \mathrm{C}$ and $650{ }^{\circ} \mathrm{C}$ ) totaling $0.63 \%$ of weight loss is probably related to the presence of absorbed ions at sample surface.

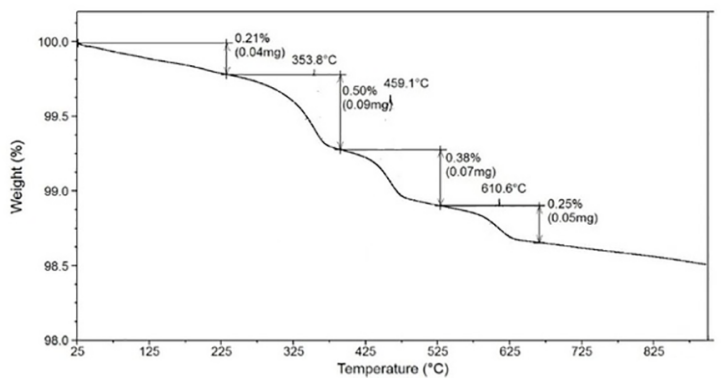

Figure 5. Thermogravimetric analysis of the calcium phosphate powder.

\subsection{FTIR characterization}

The vibrational spectrum in the infrared region (range of $4000-400 \mathrm{~cm}^{-1}$ ) of the synthesized calcium phosphate bioceramic obtained by wet precipitation is shown in Fig. 6. The energy bands related to the present vibrational groups are interpreted according to the literature as follows ${ }^{4,21-22}$. The energy bands located at 450, 480, 560, and $620 \mathrm{~cm}^{-1}$ are related to the asymmetric stretching vibrations of $\mathrm{O}-\mathrm{P}-\mathrm{O}$ of the $\mathrm{PO}^{-2}$ groups, while the band at $610 \mathrm{~cm}^{-1}$ corresponds to the O-P-O deformation of the group $\mathrm{PO}^{-3}$. The bands around $720 \mathrm{~cm}^{-1}$ and $900 \mathrm{~cm}^{-1}$ represent the symmetrical stretching of C-O of the $\mathrm{CO}^{-2}$ groups. The vibrational bands located at 960, 1010, 1030, 1070 , and $1140 \mathrm{~cm}^{-1}$ are related to asymmetric stretching of $\mathrm{PO}_{4}^{-3}$ or $\mathrm{PO}_{3}$ stretch in $\mathrm{HPO}_{3}^{-2}$. Vibrational energy band corresponding to $2360 \mathrm{~cm}^{-1}$ shows the vibration of the $\mathrm{CO}_{2}$ grouping, which presence is due to the room atmosphere where the equipment is located. The two weak energy bands located at $3410 \mathrm{~cm}^{-1}$ and $1645 \mathrm{~cm}^{-1}$ correspond to the vibrations of the $\mathrm{OH}$ groups (groups of free or hydrogen bonded hydroxyl groups with adsorbed water binding mode), showing the presence of the axial deformation of the group $\mathrm{OH}$. 


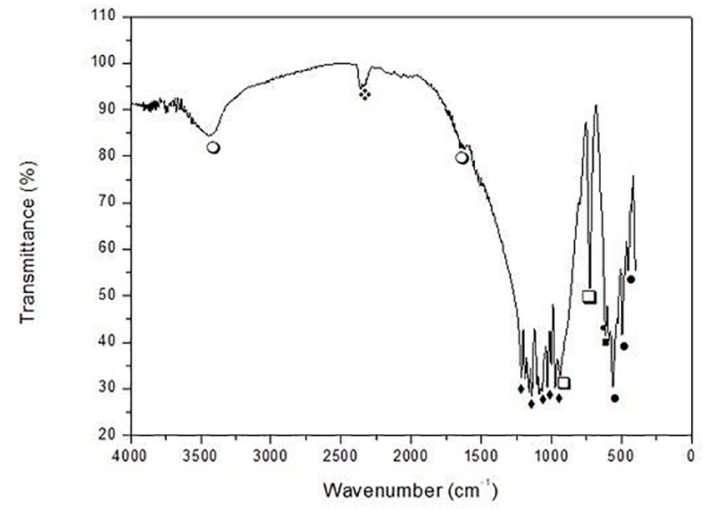

Figure 6. FTIR spectrum of the calcium phosphate powder: $\mathrm{mH}_{2} \mathrm{O}$; $\mathrm{vCO}_{2} ; \mathrm{wPO}_{3}^{-2} ; \mathrm{qCO}_{3} ; \mathrm{nPO}_{4}^{-3} ; 1 \mathrm{PO}_{4}^{-2}$.

\section{Conclusions}

The experimental results of this work indicated that the fish bone (tilapia carcass) synthesized by wet precipitation method could be a suitable source to produce new nanostructured biphasic bioceramic based on calcium phosphate. X-ray diffraction analysis and refinement by the Rietveld method indicated that the synthesized bioceramic is a biphasic mixture of $\beta$-CPP and $\beta$-TCP with major proportion of the $\beta$-CPP phase. The new biphasic calcium phosphate bioceramic presents irregular morphology, high thermal stability and nanostructured nature with a mean crystallite size of $69.58 \mathrm{~nm}$. In addition, the semiquantitative chemical analysis (SEM/EDS) indicated that the $\mathrm{Ca} / \mathrm{P}$ ratio was equal to 1.36. Therefore, the fish bone waste (tilapia carcass) has great potential for producing nanopowder of biphasic calcium phosphate bioceramic for biomedical applications, particularly for regeneration and replacement of damaged bone tissue in orthopedics and orthodontics.

\section{Acknowledgements}

The authors acknowledge the Foundation for Research Support of the State of Rio de Janeiro - Brasil (FAPERJ) Process No. E-26/203.013/2016; and National Council for Scientific and Technological Development - Brasil (CNPq) - Process No. 305928/2016-3 for supporting this work. The authors thank Flávio Ramos by the support in the SEM/EDS analysis, and also Rosane Toledo and Nathan Silva for their support in XRD analysis.

\section{References}

1. Campana V, Milano G, Pagano E, Barba M, Cicione C, Sallona G, Lattanzi W, Logroscino G. Bone substitutes in orthopedic surgery: from basic Science to clinical practice. Journal of Material Science. Materials in Medicine. 2014;25(10):24452461.
2. Tihan GT, Sereanu V, Meghea A, Voicu G, Albu MG, Mitran V, Cimpean A, Zgârian RG. Innovative methodology for developing a bone grafting composite biomaterial starting from the seashell of Rapana thomasiana. Comptes Rendus Chimie. 2017;20(4):440-445.

3. Hong Y, Fan H, Li B, Guo B, Liu M, Zhang X. Fabrication, biological effects, and medical applications of calcium phosphate nanoceramics. Materials Science and Engineering: R: Reports. 2010;70(3-6):225-242.

4. Vasant SR, Joshi MJ. Synthesis and characterization of nanoparticles of calcium pyrophosphate. Modern Physics Letters B. 2011;25(1):53-62.

5. Sun JS, Tsuang YH, Liao CJ, Liu HC, Hang YS, Lin FH. The effects of calcium phosphate particles on the growth of osteoblasts. Journal of Biomedical Materials Research. 1997;37(3):324-34

6. Lee JH, Lee DH, Ryu HS, Chang BS, Hong KS, Lee CK. Porous Beta-calcium pyrophosphate as a bone graft substitute in a canine bone defect model. Key Engineering Materials. $2003 ; 240-242: 399-402$.

7. Park JB, Lakes RS. Biomaterials: an introduction. New York: Plenum Press; 1992.

8. Hench LL. Bioceramics. Journal of the American Ceramic Society. 1998;81(7):1705-1728.

9. Safronova TV, Putlayev VI, Bessonov KA, Ivanov VK. Ceramics based on calcium pyrophosphate nanopowders. Processing and Application of Ceramics. 2013;7(1):9-14.

10. Chen C, Sun B, Li X, Li P, Guan W, Bi W, Pan Q. N-3 essential fatty acids in Nile tilapia, Oreochromis niloticus: Quantification of optimum requirement of dietary linolenic acid in juvenile fish. Aquaculture. 2013;416-417:99-104.

11. Goes ESR, Souza MLR, Michka JMG, Kimura KS, Lara JAF, Delbem ACB, Gasparino E. Fresh pasta enrichment with protein concentrate of tilapia: nutritional and sensory characteristics. Food Science and Technology (Campinas). 2016:36(1):76-82.

12. Arvanitoyannis IS, Kassaveti A. Fish industry waste: treatments, environmental impacts, current and potential uses. International Journal of Food Science and Technology. 2008;43(4):726-745.

13. Silva YS, Naval LP. Segregation of solid waste from a fishprocessing industry: a sustainable action. Revista Ambiente \& Água. 2018;13(2):e2155.

14. Shariffuddin JH, Jones MI, Patterson DA. Greener photocatalysts: Hydroxyapatite derived from waste mussel shells for the photocatalytic degradation of a model azo dye wastewater. Chemical Engineering Research and Design. 2013;91(9):16931704.

15. Corrêa THA, Holanda JNF. Calcium pyrophosphate powder derived from avian eggshell waste. Cerâmica. 2016;62(363):278280 .

16. Ofudje EA, Rajendran A, Adeogun AI, Iodwu MA, Kareem SA, Pattanayak DK. Synthesis of organic derived hydroxyapatite scaffold from pig bone waste for tissue engineering applications. Advanced Powder Technology. 2018;29(1):1-8. 
17. Gomes LC, Di Lello BC, Campos JB, Sampaio M. Synthesis and characterization of calcium phosphates produced from chicken eggshell. Cerâmica. 2012;58(348):448-452.

18. Bish DL, Howard SA. Quantitative phase analysis using the Rietveld method. Journal of Applied Crystallography. 1998;21(2):86-91.

19. Tamer M. Quantitative phase analysis based on Rietveld structure refinement for carbonate rocks. Journal of Modern Physics. 2013;4(8):1149-1157.
20. Kalita SJ, Bhardwaj A, Bhatt HA. Nanocrystalline calcium phosphate ceramics in biomedical engineering. Materials Science and Engineering C. 2007;27(3):441-449.

21. Corrêa THA, Holanda JNF. Synthesis and characterization of sustainable calcium phosphate nanopowders using eggshell waste. Trends in Physical Chemistry. 2017; 17:75-82.

22. Ebrahimi M, Botelho MG, Dorozhkin SV. Biphasic calcium phosphates bioceramics (HA/TCP): Concept, physicochemical properties and the impact of standardization of study protocols in biomaterials research. Materials Science Engineering C. 2017;71:1293-1312. 